\title{
PKC98E Regulates Odorant Responses in Drosophila melanogaster
}

\author{
(Deeta Poudel, ${ }^{1 *}$ Hao Guo, ${ }^{3 *}$ and Dean P. Smith ${ }^{1,2}$ \\ ${ }^{1}$ Department of Neuroscience, University of Texas Southwestern Medical Center, Dallas, Texas 75390-9111, ${ }^{2}$ Department of Pharmacology, \\ University of Texas Southwestern Medical Center, Dallas, Texas 75390-9111, and ${ }^{3}$ State Key Laboratory of Integrated Management of Pest Insects \\ and Rodents, Institute of Zoology, Chinese Academy of Sciences, Beijing 100101, People's Republic of China
}

Drosophila odorant receptors (Ors) are ligand gated ion channels composed of a common receptor subunit Or co-receptor (ORCO) and one of 62 "tuning" receptor subunits that confer odorant specificity to olfactory neuron responses. Like other sensory systems studied to date, exposing Drosophila olfactory neurons to activating ligands results in reduced responses to subsequent exposures through a process called desensitization. We recently showed that phosphorylation of serine 289 on the common Or subunit ORCO is required for normal peak olfactory neuron responses. Dephosphorylation of this residue occurs on prolonged odorant exposure, and underlies the slow modulation of olfactory neuron responses we term "slow desensitization." Slow desensitization results in the reduction of peak olfactory neuron responses and flattening of dose-response curves, implicating changes in $\mathrm{ORCO}^{\mathrm{S289}}$ phosphorylation state as an important modulator of olfactory neuron responses. Here, we report the identification of the primary kinase responsible for ORCO ${ }^{\text {S289 }}$ phosphorylation, PKC98E. Antiserum localizes the kinase to the dendrites of the olfactory neurons. Deletion of the kinase from olfactory neurons in the naive state (the absence of prolonged odor exposure) reduces $\mathrm{ORCO}^{\mathrm{S} 289}$ phosphorylation and reduces peak odorant responses without altering receptor localization or expression levels. Genetic rescue with a PKC98E predicted to be constitutively active restores ORCO S289 phosphorylation and olfactory neuron sensitivity to the $P K C 98 E$ mutants in the naive state. However, the dominant kinase is defective for slow desensitization. Together, these findings reveal that PKC98E is an important regulator of ORCO receptors and olfactory neuron function.

Key words: desensitization; kinase; olfaction; olfactory; orco; phosphorylation

Significance Statement

We have identified PKC98E as the kinase responsible for phosphorylation of the odorant receptor co-receptor (ORCO) at S289 that is required for normal odorant response kinetics of olfactory neurons. This is a significant step toward revealing the enzymology underlying the regulation of odorant response regulation in insects.

\section{Introduction}

In most sensory systems, the presence of background stimuli reduces the responses of the receptor neurons to subsequent stimulation (Fain et al., 2001; Kato and Touhara, 2009). In Drosophila, odorant receptors (Ors) are odorant-gated ion channels (Sato et al., 2008; Wicher et al., 2008), and how these receptors are regulated is poorly understood. Insect Ors are derived

Received Nov. 30, 2020; revised Mar. 18, 2021; accepted Mar. 22, 2021.

Author contributions: D.P.S. designed research; S.P. and H.G. performed research; S.P., H.G., and D.P.S. analyzed data; D.P.S. wrote the paper.

This work was supported by the National Institutes of Health Grant R01DC015230 (to D.P.S.). We thank Kishor Kunwar for assistance with the blinded image quantitation and generation of transgenic stocks.

*S.P. and H.G. contributed equally to this work.

The authors declare no competing financial interests.

Correspondence should be addressed to Dean P. Smith at dean.smith@utsouthwestern.edu or Hao Guo at guohaoinsect@126.com.

https://doi.org/10.1523/JNEUROSCI.3019-20.2021

Copyright $\odot 2021$ the authors from two gene families, ionotropic receptors (Irs) and Ors (Clyne et al., 1999; Vosshall et al., 1999; Benton et al., 2009). Interestingly, experience-dependent adaptation does not occur for odorants detected by the Ir receptor class of Drosophila Ors (Getahun et al., 2012; Cao et al., 2016). Ors are heteromeric membrane proteins that form an ion channel with a shared subunit, Or co-receptor (ORCO; Larsson et al., 2004) and in Drosophila, one of 62 "tuning" receptor (Or) subunits that impart ligand selectivity (Elmore et al., 2003; Hallem and Carlson, 2004). Odorant binding to the receptors triggers opening of these ion channels that freely pass calcium ions into the neurons (Sato et al., 2008; Wicher et al., 2008). While great strides have been made defining the mechanisms underlying odorant detection in insects, our understanding of the mechanisms responsible for regulation is incomplete (Wilson, 2013).

Prolonged odorant exposure $(1-30 \mathrm{~min})$ results in slow desensitization, a gradual reduction in peak spike frequencies and flattening of the dose-response curves of Drosophila 
olfactory neurons expressing ORCO (Guo et al., 2017). Blocking synaptic transmission in the ORCO primary olfactory neurons does not significantly impair slow desensitization (Guo et al., 2017), indicating it is independent of postsynaptic GABA feedback (Olsen and Wilson, 2008; Guo et al., 2017). This reveals the presence of a cell autonomous modulation mechanism that operates specifically in ORCO-expressing neurons.

We recently reported that ORCO is phosphorylated at S289 in vivo, and that phosphorylation at this position is reduced on prolonged odorant exposure (Guo et al., 2017). Furthermore, we showed that these phosphorylation changes correlate precisely with the slow desensitization modulation of olfactory neuron responses, but occur at a slower time scale than previous descriptions of desensitization in Drosophila olfactory neurons (Das et al., 2011; Nagel and Wilson, 2011; Martelli et al., 2013; GorurShandilya et al., 2017; Martelli and Fiala, 2019). Antiserum specific to the S289-phosphorylated form of ORCO (phosphoORCO) recognizes antigen in wild-type olfactory neuron dendrites in naive flies, but the phospho-signal is strikingly reduced on prolonged odorant exposure (Guo et al., 2017). Antiserum that recognizes ORCO independent of its phosphorylation state revealed that ORCO remains in the chemosensory olfactory neuron dendrites following prolonged odorant exposure, ruling out a receptor translocation mechanism for slow desensitization (Guo et al., 2017). These findings led us to propose a model for slow desensitization in which ORCO is phosphorylated in the naive, maximum sensitivity state, and becomes dephosphorylated on odorant exposure to modulate olfactory neuron responses. However, the enzymology underlying this regulation is a mystery. Here, we identify PKC98E as the primary kinase required for ORCO S289 phosphorylation.

\section{Materials and Methods}

\section{Drosophila stocks}

An isogenized strain of $w^{1118}$ was used as a wild-type control for most experiments. Male flies were used for most experiments, but females were found to have similar responses. UAS-FLP and UAS-RNA $i$ flies to knock-down candidate kinases were obtained from the Bloomington and Vienna Stock centers. Other stocks include CAMI RNAi: BS ${ }^{\#} 26726$; CAMII RNAi: BS 29401 ; PKA-C1 RNAi: BS ${ }^{\#} 5355$; PKA-C3 RNAi: $\mathrm{BS}^{\#} 27569 ;$ PKA-R1 RNAi: $\mathrm{BS}^{\#} 27308 ;$ PKA-R2 RNAi: $\mathrm{BS}^{\#} 27680 ; N r k$ RNAi: BS ${ }^{\# 6936 ;}$ CKII $\beta$ : BS\#42943; CKII $\alpha$ : VDRC \#330507; Asator BS\#57033; Phky: BS\#42500; Fray: VDRC\#106919; Stlk: BS\#35186; Slob: VDRC\#39812; PDK: VDRC\#37968; CG17698: VDRC\#35634; Par-1: BS\#32101; Gprk1: BD\#36246; LK6: BS\#28357; da-Gal4: BS\#51669). nosCas9 flies $\left(y, s c, v\right.$; $+\operatorname{attp} 2\left(y^{+}\right)$nos-Cas $\left.9 v^{+}\right)$were generated by Kondo and Ueda (2013) and kindly provided by Michael Buszczak. orco ${ }^{2}$ mutants and pOrco-GAL4 flies were provided by Leslie Vosshall. UAS$t d G F P$ flies (Han et al., 2011) were obtained from Robin Hiesinger. UAS$\operatorname{Orco}^{\text {S289A }}$ was described previously (Guo et al., 2017).

\section{RNA-Seq}

Ten micrograms of total RNA was extracted from four sets of flies, each from $\sim 1000$ antennae using TRIzol reagent (Invitrogen). Poly-A RNA was purified and fragmented followed by reverse transcription. A-tailed cDNA was ligated to adapters, amplified by PCR, and purified with Ampure XP beads. Four independent samples were submitted for sequencing. Samples were applied to Illumina Hiseq 2500 and were sequenced from one end. The four independent sequencing runs yielded 47.9 million, 52.1 million, 43.3 million, 56.7 million reads, respectively.

Single sensillum electrophysiology

Single sensillum recordings (SSRs) were performed as previously described (Laughlin et al., 2008; Pitts et al., 2016). Briefly, filtered AC signals $(200 \mathrm{~Hz}$ to $3 \mathrm{kHz})$ were recorded and digitized for analysis (Autospike 3.2). Flies were housed in fresh vials containing standard yeast molasses food in small groups before SSR recordings. Compounds used in SSRs and for odor exposure were of the highest purity available (SigmaAldrich and Pherobank BV). A total of $30 \mu \mathrm{l}$ of diluted or undiluted odorant were placed on a small piece of Wattman paper $\left(1.5 \mathrm{~cm}^{2}\right)$ inserted into a 5.75-inch Pasteur pipette and 300-ms puffs of air, controlled by a computer activated valve, were passed over the filter into a constant stream (30 $\mathrm{ml} / \mathrm{s}$ ) of charcoal filtered, humidified air passing over the preparation. The odorant concentration in all figures represents the dilution of odorant blotted onto Wattman paper over which air puff stimuli were passed. The actual concentration reaching the antenna is much less. The change in spikes per second ( $\Delta$ spikes) was plotted as a sigmoidal curve with Hill fitting. The $\Delta$ spikes were calculated as: $\Delta$ spikes $=$ (number of spikes stimulated by odorant in the first sec) - (number of spikes/s averaged over $10 \mathrm{~s}$ before the stimulus).

\section{Odorant exposure experiments}

Flies were transferred to a new standard food vial supplemented with $200-\mu \mathrm{l}$ water for $2 \mathrm{~h}$. For prolonged odorant exposures, a piece of filter paper $\left(1.5 \mathrm{~cm}^{2}\right)$ with $30 \mu \mathrm{l}$ of $10-30 \%$ corresponding odorant diluted in paraffin oil was placed in the food vials. Following specified exposure times, the flies were immediately used for electrophysiology or flash-frozen in liquid nitrogen and processed for sectioning for immunofluorescence.

\section{Frozen tissue sections and immunocytochemistry}

For anti-PKC98E antiserum, three- to six-week-old female NZW Rabbits were immunized with KLH (Sigma) conjugated peptides corresponding to the $\mathrm{C}$ terminus of PKC98E (sequence $\mathrm{N}$ EFAGFSFVNPKFGPERKVY-C) using formaldehyde followed by extensive dialysis against PBS. Rabbits were immunized with the conjugated peptide in Freunds adjuvant as previously described (Smith et al., 1991). Serum from immunized animals was affinity purified using the peptide bound to Affigel 10 columns (Bio-Rad). The antiserum was used at 1:300 dilution in PBS $0.1 \%$ saponin for immunostaining. The phospho-specific antibody was previously described in Guo et al. (2017) and was diluted 1:20 in PBS, 0.1\% saponin. Total ORCO antiserum (Guo et al., 2017), that detects ORCO independent of phosphorylation state, was diluted 1:300 for immunostaining. Hand-dissected heads were fixed in $4 \%$ paraformaldehyde (PFA; Sigma) $1 \times$ PBS, pH 7.4 for $2 \mathrm{~h}$ on a rotator at $4^{\circ} \mathrm{C}$ followed by impregnation in $25 \%$ sucrose overnight in $0.1 \mathrm{M} \mathrm{Na}_{2} \mathrm{PO}_{4}, \mathrm{pH} 7.4$. For frozen tissue sections, samples were imbedded in Tissue-Tek (Sakura Finetek), and $10-\mu \mathrm{m}$ sections were obtained using a microtome (Bright Instrument Company). Sections were air dried for $1 \mathrm{~h}$ at room temperature, postfixed in 4\% PFA, $1 \times$ PBS for 5 min, incubated with $0.5 \%$ Triton X-100 (Sigma), 0.1\% saponin (Fluka) in $1 \times \mathrm{PBS}, \mathrm{pH} 7.4$ for $5 \mathrm{~min}$, and washed three times with $0.1 \%$ saponin in $1 \times$ $\mathrm{PBS}, \mathrm{pH}$ 7.4. The sections were incubated with diluted primary rabbit antibody overnight at $4^{\circ} \mathrm{C}$. After 4 - to 10 -min washes, sections were incubated with a 1:500 dilution of Alexa Fluor 543-conjugated goat anti-rabbit antibodies (Invitrogen) for $2 \mathrm{~h}$ at room temperature. Slides were washed in PBS $0.1 \%$ saponin four times and mounted in glycerol mounting medium (Dako).

\section{Imaging and image quantification}

Confocal images were obtained using Zeiss LSM 510 and LSM710 confo$\mathrm{cal}$ microscopes. Identical imaging settings on the same microscope were used for comparisons among genotypes. Olfactory neuron dendrite fluorescence intensity was quantified based on the mean pixel value (the sum of pixel value of selected area divided by the total number of pixels) using ImageJ (http://imagej.nih.gov/ij/). The background pixel value from an identical area was subtracted. All quantification was performed by a technician blinded to genotypes. The Student's $t$ test for statistical significance was conducted using Origin 8.0 and ANOVA was implemented using the SPSS package (IBM).

\section{Generation of PKC98E conditional mutant}

Primers encoding the PKC98E kinase domain and FRT sites were used to amplify the PKC98E kinase domain from genomic DNA. The kinase domain was sequenced and cloned into pHD-DsRed vector (Gratz et al., 
2013). The 1-kb upstream and downstream homology region flanking the PKC98E kinase domain was introduced in $\mathrm{pHD}$ DsRed vector. This construct was then co-injected with two CRISPR targeting plasmids flanking the kinase domain (Gratz et al., 2013). Flies were selected for RFP expression in the eyes and correct integration and presence of FRT sites were confirmed by PCR and sequencing. To eliminate PKC98E from olfactory neurons, we expressed UAS-FLP recombinase in olfactory neurons using $p O R C O-G A L 4$ in flies homozygous for the PKC98E FRT allele ( $p$ Orco-GAL4; PKC98E FRT, UAS-FLP). Flies were assayed at one week of age to allow any previously synthesized PKC98E to turn over.

The primers used to clone the kinase domain are 5'-TTAATTAACGACGGTTTAT CAACTAATTAC and 5' CTCGAGCCGCG GGAAGTTCCTATTCTCTAGAAAGTATAG GAACTTC GCATCGCAATCCATCGAACTG (containing underlined FRT site).

The primers used for the upstream homology domain are 5'-GCTAGCAGCTGCTC AGCTCTGGCGCTTC and 5'-TTAATTAA GAAGTTCCTATTCTCTAGAAAGTATAGG AACTTCACTGTTTCTTGCTGTGCAGTGTG (containing underlined FRT site), and for the downstream homology 5'-ACTAGTTGTTGG AATTCATTTATGTTGTTTGC and 5' - CCCT CGAGGGAGTAAATAATAATCGTAAC

The primers to target Cas9 to the upstream cleavage site are $5^{\prime}$-CTTCGCACAGCAAGAA ACAGTCGA and 5'-AAACTCGACTGTTTC TTGCTGTGC and for the downstream cleavage site, 5'-CTTCGCTTCAAGCTCCACGCC TGT and $5^{\prime}$-AAACACAGGCGTGGAGCTTG AAGC.

The primers used to confirm correct integration depicted in Figure $4 A$ are: P1 $\left(5^{\prime}-\mathrm{TC}\right.$ AACCCACCTTCTGTTCGC-3'), P2 (5' -GCTT CGAGCCGATTGTTTAG-3'), P3 (5' - GCTAA ACAATCGGCTCGAAG-3'), P4 (5'-CCAGCA GCGATTGACCTATT-3').

Generation of PKC98E ${ }^{\text {CAAX }}$ mutants

PKC98E RB cDNA encoding a PKC98E splice form that lacks the regulatory domain was isolated from Drosophila head RNA by RT-PCR, cloned, and sequenced. This cDNA was used as a template to add the sequence of a prenylation signal, VQCASQ (Berger et al., 2018) to the C terminus of the coding sequence using the primers $5^{\prime}$-GAATTCAAATGACAAGTTCA and 5'-CTCGAGTTACTGGCTGGCGCACTGCA CGTAGACTTTGCGCTCCGG. This construct was cloned into pUAS (Brand and Perrimon, 1993) and transgenic flies produced by standard techniques (Spradling and Rubin, 1982).

Experimental design and statistical analyses

SSRs were performed on 2- to 6-d-old flies. To avoid sensory adaptation during recordings, the stimuli were separated by an interval of at least $1 \mathrm{~min}$, and each fly was only used for one dose-response recording. One way-ANOVA with post hoc Tukey's test was used for the comparison of responses to odorants between multiple genotypes. For measuring the desensitization, flies were preexposed with $30 \mu \mathrm{l}$ of $30 \% \mathrm{cVA}$ in a small
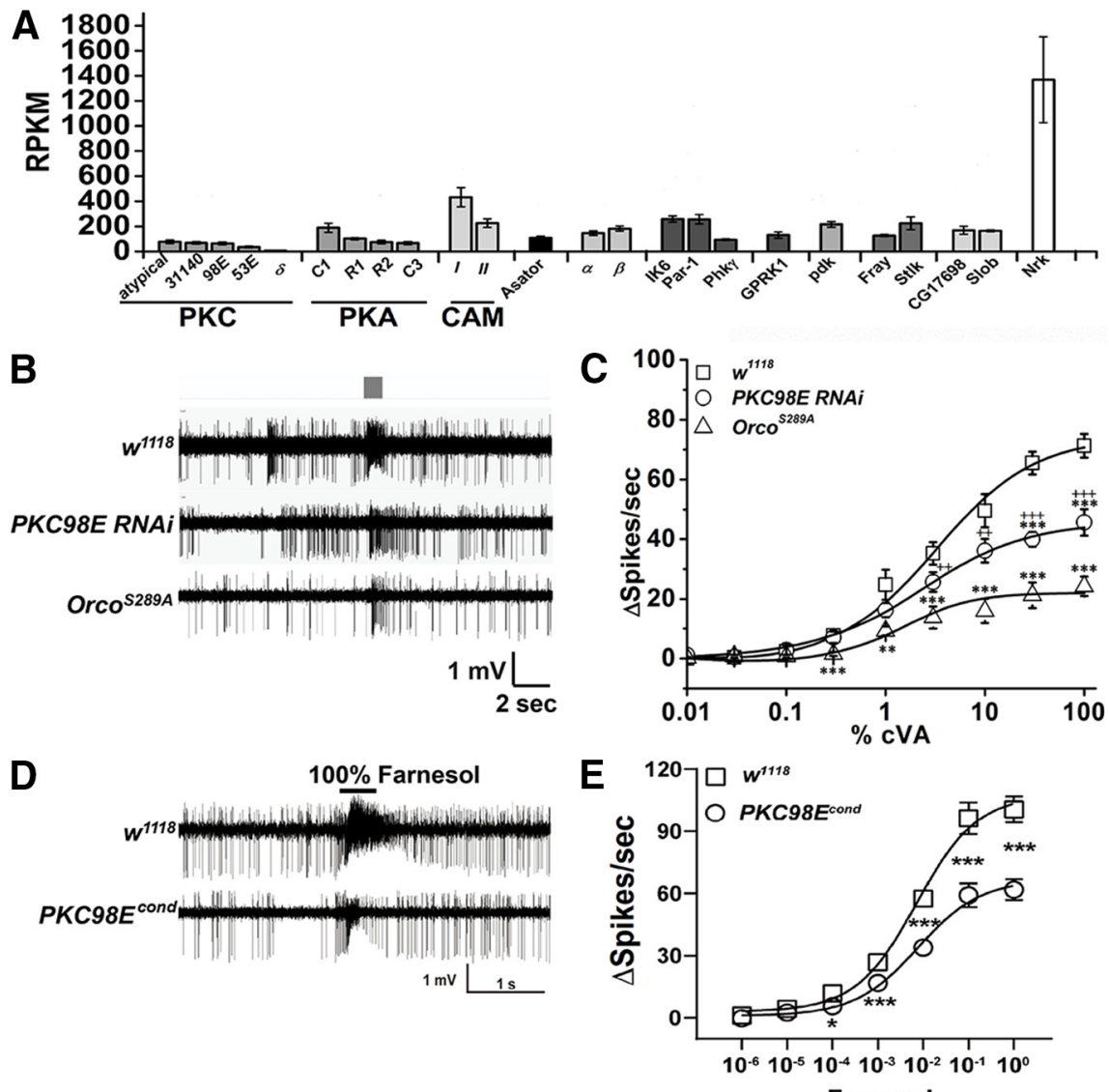

Farnesol

Figure 1. PKC98E is required for normal CVA sensitivity. $\boldsymbol{A}$, RNAseq reads for antennal kinases. The RPKM reflects the abundance of each kinase RNA. Error bars represent SEM for four replicates. $\boldsymbol{B}$, Sample traces from the at1 neurons stimulated with 1\% cVA pheromone for $300 \mathrm{~ms}$ (gray box) from $w^{1118}$ control, PKC98E RNAi flies (p0RCO-GAL4/UAS-PKC98E RNAi) and $O R C O^{S 289 A}$ flies ( $p O R C O-G A L 4 / U A S-O R C O^{S 289 A} ;$ orcO $^{2}$ ). \% indicates dilution of $C$ A in diluent spotted on Wattman paper and not the actual odorant concentration (see Materials and Methods). Traces for other kinases are presented in Extended Data Figure 1-1. C, PKC98E RNAi shows a reduction in peak response and dose-response curve flattening to CVA pheromone $(n=5)$. The sigmoidal curve for $\Delta$ spikes was plotted for different concentrations of cVA with Hill fitting for the genotype described. Error bars represent SEMs. One-way ANOVA analysis with post hoc Tukey's HSD test was done between control $\left(w^{1118}\right)$, PKC98E RNAi and ORCO $0^{5289}$; $* * p<0.05, * * * p<0.01$. The ANOVA comparison was also done between ORCO $289 \mathrm{~A}$, and PKC98E RNAi; $++p<0.05,+++p<0.01$ (actual $p$ values for PKC98E RNAi and wild-type controls: for $0.01 \%, 0.03 \%, 0.1 \%, 0.3 \%, 1 \%, 3 \%, 10 \%, 30 \%$, and $100 \%$ cVA for are $0.54,0.95,0.90,0.814,0.125,0.085,0.070$, $1.4 \times 10^{-4}$, and 0.002 , respectively; $p$ values for pORCO-GAL4/UAS-ORCOS289A; orco and controls for $0.01 \%, 0.03 \%, 0.1 \%$, $0.3 \%, 1 \%, 3 \%, 10 \%, 30 \%$, and 100\% cVA for are 0.92,0.82,0.59,0.002,0.033,0.005,0.0025, $1.13 \times 10^{-4}$, and $4.92 \times 10^{-5}$. For ANOVA comparison between PKC98E RNAi expressed with pORCO-GAL4 and pORCO-GAL4/UAS-ORCO ${ }^{\text {S289A. }}$ orco $^{2}, p$ values are $0.35,0.92,0.41,0.064,0.068,0.047,0.0095,0.0025$, and 0.0091 for $0.01 \%, 0.03 \%, 0.1 \%, 0.3 \%, 1 \%$, $10 \%, 30 \%$, and $100 \%$ cVA. D, E, Farnesol-induced response from ai2a intermediate sensilla neurons (also called at2a neurons (Couto et al., 2005; Ronderos et al., 2014) from $w^{1118}$ and $P K C 98 E^{\text {cond }}$ (for olfactory neuron-specific null mutants, see Fig. 4) reveal similar defects as CVA-induced pheromone responses. $\boldsymbol{D}$, Representative traces of the response of $w^{1118}$ and $P K C 98 E^{\text {cond }}$ to farnesol. $\boldsymbol{E}$, Dose-response curves from ai2a neurons of $w^{1118}$ (open square) and $P K C 98 E^{\text {cond }}$ (open circle) flies to a series of farnesol dilutions. Significant differences in sensilla responses were detected at the dilutions of $10^{-4}(p=0.014), 10^{-3}$ $\left(p=4.227 \times 10^{-4}\right), 10^{-2}\left(p=2.429 \times 10^{-5}\right), 10^{-1}(p=0.001)$, and pure farnesol $\left(p=1.440 \times 10^{-5}\right) ; n=10$ for each genotype; $* p<0.05, * * p<0.001, * * * p<0.0001$ by one-way ANOVA. Data were plotted as mean \pm SEM.

vial for $1 \mathrm{~h}$, and controls were preexposed with the solvent-paraffin oil. To mitigate the effect of recovery, the recording was completed within $15 \mathrm{~min}$ of removal from the stimulus vial. Two-tailed Student's $t$ test was used to test for statistical significance of slow desensitization (reduction in peak spikes/s) between $w^{1118}$ or PKC98E ${ }^{C A A X}$, and two-way ANOVA was used to test the statistical significance of interactions between desensitization among genotypes. For immunostaining comparisons, 2- to 6-d-old flies were used and images were taken under the identical settings. One-way ANOVA was used to compare the fluorescent intensity between genotypes. One-way ANOVA was performed with Origin 8.0 (OriginLab). Two-tailed Student's $t$ test and two-way ANOVA were performed with GraphPad Prism 8 software (GraphPad Software) or SPSS (IBM). 


\section{Results}

PKC98E is implicated in modulating odorant responses

We used RNA-seq to identify kinase genes expressed in adult antenna mRNA. Hand-dissected antennae were subjected to RNA extraction and purification, and were subsequently barcoded and sequenced. Of the 239 known kinases in the Drosophila genome (FlyBase Consortium, 1999), we identified 21 serine/threonine kinases with expression levels averaging over 10 reads per kilobase per million sequence reads (RPKM) over four independent experiments (Fig. 1A). To identify which of these 21 candidates might functionally contribute to ORCO S289 phosphorylation and odorant sensitivity regulation, we used transgenic RNA interference to individually knock-down each candidate kinase in the ORCO-expressing olfactory neurons in vivo. We measured the electrical responses from the cVA-sensing Or67d neurons using SSRs to determine whether any of the kinase RNAi knock-down constructs impacted the olfactory responses (Fig. 1; Extended Data Fig. 1-1). Expression of PKC98E RNAi in the olfactory neurons resulted in a striking defect in the dose-response curves to cVA stimulation in at 1 neurons. The maximum spike frequency to $\mathrm{cVA}$ stimulation was reduced almost 2-fold (Fig. 1C). None of the other individual kinase RNAi constructs produced statistically significant changes in cVA responses (Extended Data Fig. 1-1). However, ORCO ${ }^{\text {S289A }}$ mutants (Guo et al., 2017) that are incapable of being phosphorylated at this position, have even lower peak responses (Fig. 1C). This difference could indicate that other kinases are capable of phosphorylating ORCO at S289, that the RNAi is not completely penetrant, or that the ORCO ${ }^{\text {S289A }}$ mutant has lower intrinsic sensitivity than dephosphorylated wild-type ORCO. The modulatory phenotype is not restricted to pheromone-sensing neurons, as similar effects are observed in farnesol-sensing neurons (Fig. 1D,E).

\section{ORCO phosphorylation at $\mathrm{S} 289$ is reduced in PKC98E RNAi flies}

We next asked whether the reduced peak sensitivity we observed to cVA stimulation in PKC98E RNAi flies was associated with reduced ORCO S289 phosphorylation. Using phospho-specific ORCO antiserum (Guo et al., 2017), we quantified ORCO phosphorylation at S289 in wild-type and PKC98E RNAi olfactory neurons from naive flies. Figure 2 shows that PKC98E RNA $i$ flies have a significant reduction in phospho-ORCO signal (Fig. $2 B, E$ ) compared with controls (Fig. $2 A, E$ ). RNAi transgenes to $\delta P K C$ and PKC53E, two PKC family members that were previously implicated in olfactory function (Getahun et al., 2016) had no effect on $\mathrm{ORCO}^{\mathrm{S} 289}$ phosphorylation (Fig. 2C-E). Furthermore, using antiserum that recognizes ORCO independent of phosphorylation state, we observed no change in the total ORCO levels in the olfactory neuron dendrites (Fig. $2 F-J$ ). Therefore, the reduction in phospho-ORCO is not because of translocation of ORCO protein stemming from a function of PKC98E. We conclude that PKC98E is required for normal phosphorylation of ORCO at S289 in vivo.

\section{Antiserum to PKC98E identifies olfactory neuron dendrite} expression

We generated antiserum to a C-terminal peptide specific to PKC98E to localize the kinase in the olfactory neurons (see Materials and Methods). The antiserum detects kinase protein in the olfactory neuron dendrites from wild-type olfactory neurons
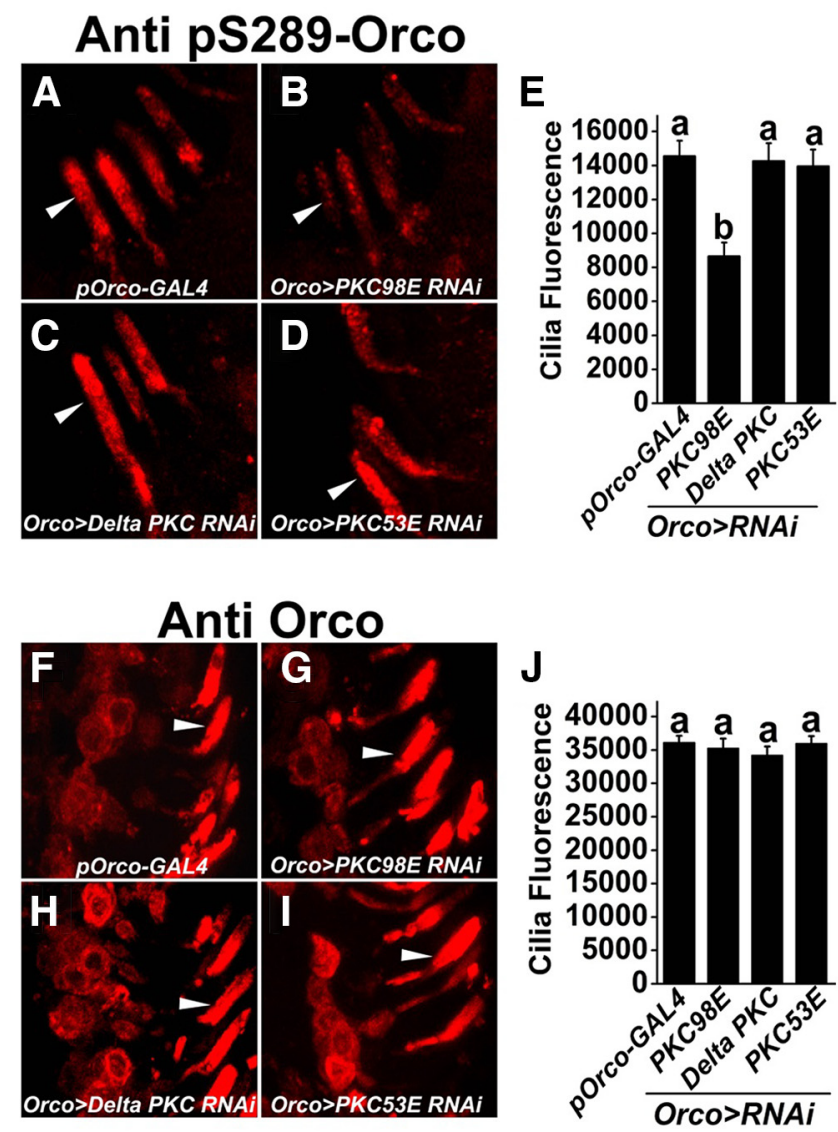

Figure 2. PKC98E is required for normal phosphorylation of ORCO at $S 289$ in vivo. $\boldsymbol{A}-\boldsymbol{D}$, Representative images showing the phosphorylation of ORCO at S289 in the $(\boldsymbol{A})$ pORCO-GAL4 control, (B) PKC98E knock-down, (C) $\delta$ PKC knock-down, and (D) PKC53E knock-down (all expressed with $P O R C O-G A L 4)$. Arrowheads indicate olfactory neuron dendrites. $\boldsymbol{E}$, The phosphorylation of ORCO ${ }^{5289}$ is significantly reduced in PKC98E knock-down ( $b$ over error bar; $p=$ $1.66 \times 10^{-7}$ for PKC98E RNAi compared with pORCO-GAL4 control). There is no significant difference between PORCO-GAL4 and $\delta$ PKC RNAi (a over error bar; $p=0.90$ ) or PKC53E RNAi, $p=0.99$. PKC98E RNAi is different from $\delta$ PKC RNAi $\left(p=4.22 \times 10^{-6}\right)$ and PKC53E $\left(p=3.11 \times 10^{-7}\right)$, but there is no difference between PKC53E RNAi and $\delta$ PKC RNAi $(p=0.96)$. Analysis was performed using one-way ANOVA with post hoc Tukey's HSD test. $\boldsymbol{F}-\boldsymbol{I}$, Representative images showing total ORCO localization in the $(\boldsymbol{F})$ control, $(\boldsymbol{G})$ PKC98E RNAi, (H) $\delta$ PKC RNAi, and (I) PKC53E RNAi. Arrowheads denote representative olfactory neuron dendrites. $J$, The quantification shows the overall localization of ORCO in the olfactory neuron dendrites is unaffected in the kinase RNAi lines. Analysis was performed using oneway ANOVA with post hoc Tukey's HSD test ( $p=0.94$ for PKC98E RNAi vs pORCO-GAL4; $p=0.36$ for $\delta$ PKC RNAi vs $p$ ORCO-GAL4; $p=0.82$ for PKC53E RNAi vs $p$ ORCO-GAL4; $p=0.71$ for PKC98E RNAi vs $\delta$ PKC RNAi; $p=0.82$ for PKC98E RNAi vs PKC53E RNAi; and $p=0.99$ for PKC53E RNAi vs $\delta$ PKC RNAi ( $n=15$ for each genotype). Data are plotted as mean \pm SEM.

(Fig. 3D,F), and these signals are dramatically reduced in the PKC98E RNAi knock-down (Fig. 3I). These results confirm the antiserum is specific to PKC98E and that the PKC98E kinase is normally localized to the site of olfactory signal transduction.

\section{Generation of PKC98E mutants}

RNAi often produces hypomorphic phenotypes, and can produce off-target effects. Therefore, we sought to confirm our finding that PKC98E is an important olfactory neuron regulator by generating null mutants defective for PKC98E expression. Previous studies showed PKC98E has essential functions in development regulating dorsal-ventral patterning (Tremmel et al., 2013). Consistent with this data, frame-shift mutants in PKC98E generated using CRISPR non-homologous ends joining are lethal (data not shown). Therefore, to examine the loss of function 
phenotype of PKC98E in the olfactory neurons without disrupting developmental functions, we generated PKC98E conditional mutant flies that lack PKC98E function exclusively in ORCO-expressing olfactory neurons.

We used CRISPR/Cas9-mediated homologous recombination editing to replace the endogenous $P K C 98 E$ kinase domain with one flanked by FRT recombination sites (Fig. 4A,B; Materials and Methods). The homozygous PKC98E FRT flies are homozygous viable, fertile and healthy, indicating that introduction of the FRT sites in the non-coding DNA flanking the kinase domain does not impair PKC98E function. Furthermore, PKC98E FRT flies have cVA doseresponse curves that are not statistically different from wild-type controls (Fig. 4C). Driving FLP with the daughterless promoter in the PKC98E FRT homozygous background was lethal, consistent with the developmental requirement of PKC98E (data not shown). To eliminate PKC98E specifically from the olfactory neurons, we crossed the FLP recombinase gene expressed under control of the ORCO promoter in the PKC98E FRT homozygous mutant background. In this stock, FLP recombinase expression is restricted to the ORCO-expressing olfactory neurons and is expected to excise the DNA encoding the PKC98E kinase domain from the genome of these olfactory neurons. Figure $4 D-G$ shows that pORCO-GAL4; PKC98E FRT, UAS-FLP (referred to as PKC98E conditional) effectively eliminates PKC98E antigen from the olfactory neurons.

We next examined the contribution of PKC98E to ORCO $^{\text {S289 }}$ phosphorylation in the PKC98E FRT conditional null mutants. Figure 5 shows that compared with wild-type naive flies, ORCO phosphorylation at S289 is reduced to approximately one-fifth of normal in PKC98E FRT conditional naive flies. This reveals that PKC98E is normally required for full phosphorylation of ORCO at S289. The residual phosphorylation signal in the conditional mutants suggests another kinase is capable of phosphorylating ORCO at S289 at a low level, or perhaps some cells still have PKC98E persisting from before FLP expression. Antiserum to total ORCO shows no significant difference in ORCO levels or location (Fig. $5 H, I$ ), confirming that PKC98E does not affect sensitivity through translocation of ORCO out of the olfactory neuron dendrites. Next, we tested the odorant responses of the PKC98E FRT conditional mutants. Loss of PKC98E function in the conditional allele results in a similar reduction in peak responses compared with the PKC98E RNAi flies in the dose-response curves to $\mathrm{cVA}$, peaking at around 30 spikes/s at $100 \% \mathrm{cVA}$ (Fig. 6B). However, the impairment of cVA response in the conditional mutant of $P K C 98 E$ is not quite as severe as we see in $O R C O^{S 289 A}$ mutants. These data demonstrate that
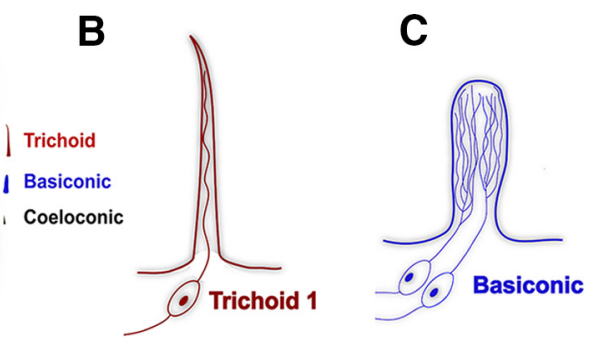
Cartoon depicting the Drosophila antenna with location of different sensilla. $\boldsymbol{B}$, Cartoon showing the olfactory neuron anatPKC localizes PKC98E (red) to the olfactory neuron dendrites (arrowhead) and a round structure between the of the olfactory neuron dendrites and the cell body (arrow). $\boldsymbol{E}$, Green is membrane-anchored tdGFP (Han et al., 2011) 作 PKC98E and tdGFP in the olfactory neuron dendrites. G, Preimmune serum from the same rabbit later immunized against PKC98E peptide does not detect antigens in Drosophila antenna. $\boldsymbol{H}$, PKC98E localization in $w^{1118}$ control. $\boldsymbol{I}$, Flies expressing PKC98E RNAi with the ORCO promoter have reduced PKC98E signal. Scale bars: $10 \mu \mathrm{m}(\boldsymbol{D})$ and $20 \mu \mathrm{m}(\mathbf{G}-\mathbf{I})$.

$\mathrm{PKC} 98 \mathrm{E}$ is the major $\mathrm{ORCO}^{\mathrm{S} 289}$ kinase and is required for normal odorant responses in olfactory neurons.

We next tested whether an active, membrane-tethered version of PKC98E could rescue ORCO S289 phosphorylation and odorant sensitivity in the PKC98E conditional mutants. We started with a splicing variant of $P K C 98 E, P K C 98 E-R B$, that has an alternate $5^{\prime}$ splicing arrangement that produces a $\mathrm{PKC} 98 \mathrm{E}$ protein that lacks the regulatory domain (Thurmond et al., 2019). The regulatory domain includes a pseudosubstrate domain that maintains the kinase in the inactive state in the absence of activating factors, and PKCs lacking the regulatory domain are constitutively active (Sommese et al., 2017). To tether the kinase to the membrane, we modified the PKC98E- $R B$ cDNA to include a CAAX prenylation signal at the $\mathrm{C}$ terminus (Schafer et al., 1989). We named the kinase encoded by this construct PKC98E ${ }^{\text {CAAX }}$. We crossed UAS-PKC98E $E^{C A A X}$ into the PKC98E FRT conditional mutant background. We examined ORCO S289 phosphorylation, comparing the PKC98E conditional mutants to PKC98E conditional mutants also expressing $P K C 98 E^{C A A X}$. We observed restoration of the ORCO S289 phosphorylation in the presence of PKC98 $\mathrm{E}^{\mathrm{CAAX}}$ (Fig. $7 B-D$ ). We next tested the cVA sensitivity 

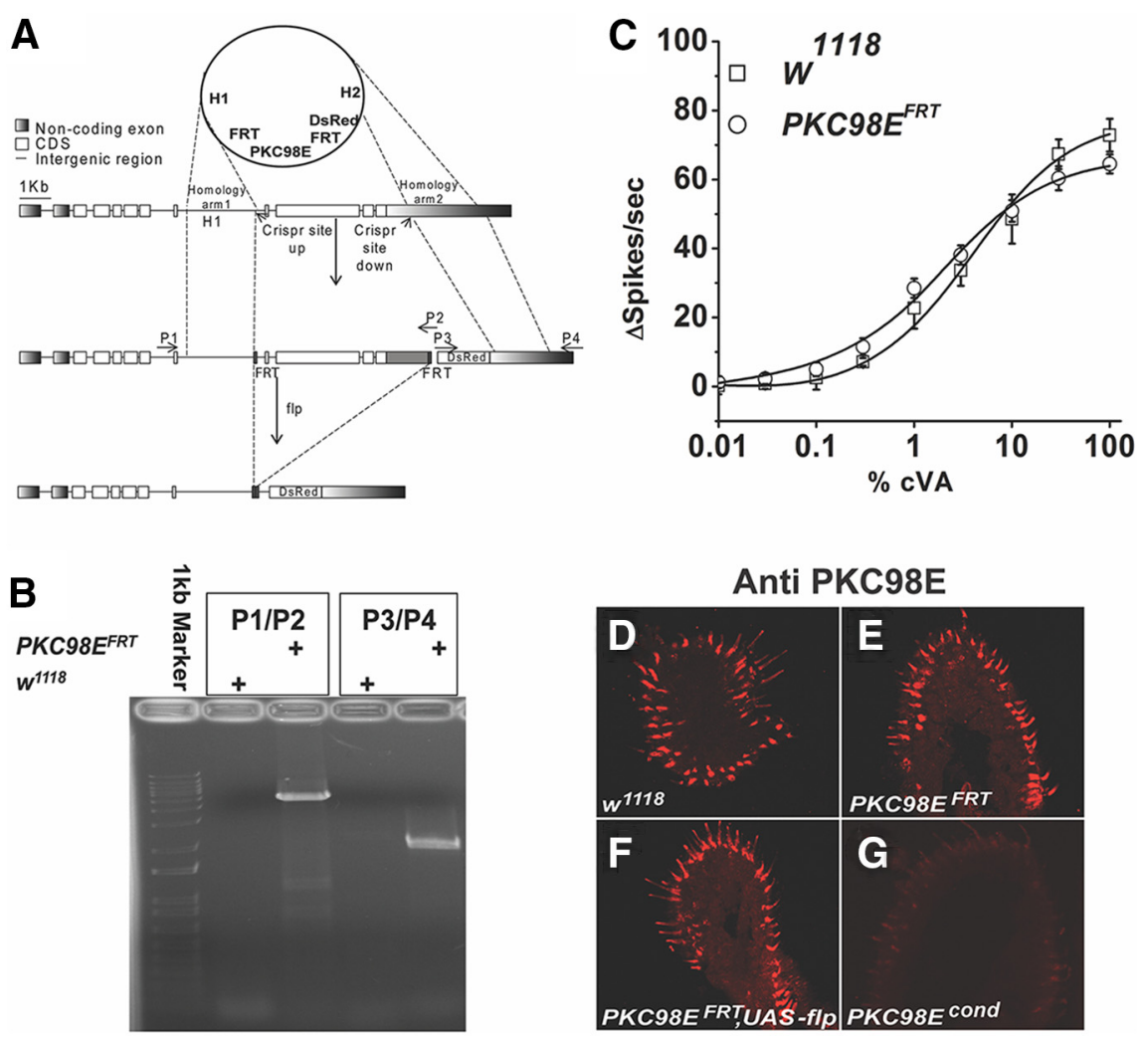

Figure 4. Generation of PKC98E conditional null mutant. $A$, CRISPR/Cas9 was used to engineer FRT sites upstream and downstream of the DNA encoding the kinase domain of PKC98E (see Materials and Methods). Flies homozygous for the PKC98E FRT allele are viable and healthy. Loss of function for PKC98E in olfactory neurons was produced by introducing a transgene encoding the FLP recombinase expressed under control of the ORCO promoter. H1, homology arm 1; H2, homology arm 2; dsRed, RFP reporter gene; FRT, FLP recombination sites; P1-P4 represent PCR primer binding sites. $B, P C R$ to validate the correct integration of the FRT allele using P1-P4 primers. C, Dose-response curve to CVA shows the FRT insertions do not alter cVA odor sensitivity in the PKC98E FRT flies in absence of the FLP recombinase $(n=5)$. The sigmoidal curve for $\triangle$ spikes with Hill fitting was plotted for different concentrations of cVA for the $w^{1118}$ and PKC98E FRT flies $(p=0.75,0.59,0.52,0.25,0.33,0.39,0.39,0.73,0.25$, and 0.13 for $0.01 \%, 0.03 \%, 0.1 \%, 0.3 \%, 1 \%, 3 \%, 10 \%$, and 100\% cVA. D-G, PKC 98 E immunoreactivity in the conditional allele. D, $w^{1718}$. E, PKC98E FRT. F, PKC98E FRT, UAS-FLP. G, PKC98E FRT conditional (pORCO-GAL4; PKC98E FRT, UAS-FLP).

of PKC98E FRT conditional mutant flies also expressing $P K C 98 E^{C A A X}$. PKC98E $E^{C A A X}$ restored the naive cVA doseresponse curves and peak responses of the olfactory neurons to levels that were not statistically different from wild-type controls, but were different from PKC98E conditional mutants alone (Fig. $7 E, F)$. We conclude that $\mathrm{PKC} 98 \mathrm{E}^{\mathrm{CAAX}}$ is able to revert the effects of the PKC98E loss of function mutant on ORCO phosphorylation and restore naive olfactory neuron responsiveness.

Finally, while PKC98E $\mathrm{E}^{\mathrm{CAAX}}$ is capable of rescuing the naive response defects in the PKC98E conditional background, because it is unregulated it might be defective for restoring slow desensitization to prolonged odorant exposure. We compared the responses of wild-type controls and PKC98E conditional mutants expressing PKC98E ${ }^{\text {CAAX }}$ with and without a prolonged odor preexposure (Fig. $7 G, H$ ). Remarkably, we find that the flies expressing the constitutive kinase fail to reduce olfactory neuron responsiveness on prolonged odorant stimulation.

\section{Discussion}

We have identified PKC98E as the primary kinase responsible for the phosphorylation of ORCO at S289. Loss of the kinase activity in olfactory neurons impairs the naive peak odorantinduced responses in olfactory neurons. This phenotype is similar to that of wild-type olfactory neurons following prolonged odorant exposure and flies unable to phosphorylate ORCO at S289. The loss of responsiveness in all three cases is correlated with impaired phosphorylation of ORCO at S289.
ORCO is likely to be a direct phosphorylation target of PKC98E, based on co-location of both factors in the olfactory neuron dendrites, loss of ORCO phosphorylation in the PKC98E FRT conditional mutants, rescue of ORCO phosphorylation by expression of the PKC98E kinase domain using the PKC98E ${ }^{C A A X}$ allele, and the fact that ORCO S289 is predicted to be a direct PKC phosphorylation target (Blom et al., 1999). It is possible that $\mathrm{PKC} 98 \mathrm{E}$ regulates ORCO indirectly, with $\mathrm{PKC} 98 \mathrm{E}$ regulating another kinase that phosphorylates ORCO. However, this is unlikely given no other kinase expressed in the antenna had a similar defect in the RNAi experiments.

Interestingly, we observe a residual amount of phosphoORCO S289 in the PKC98E FRT conditional mutants. A different kinase might be capable of phosphorylating ORCO at S289, or perhaps some PKC98E enzyme persists in the conditional mutant that is not readily detectable with our antiserum. It seems reasonable to speculate that the differences in the dose-response curves between these ORCO ${ }^{S 289 A}$ and the PKC98E conditional mutants is because of the residual phosphorylation we observe.

Different members of the Drosophila PKC family have been previously implicated in regulating insect odorant responses through ORCO phosphorylation (Sargsyan et al., 2011; Getahun et al., 2016). These studies concluded PKC activity enhances ORCO sensitivity and that ORCO phosphorylation increases on odorant stimulation (Getahun et al., 2013). We concur with the conclusion that ORCO phosphorylation enhances ORCO receptor sensitivity, but subsequent work has shown that ORCO 
phosphorylation is reduced on odorant exposure at the critical residue S289 (Guo et al., 2017). The effect of PKC activator and inhibitor drugs (including the $\mathrm{PKC} \alpha$ inhibitor Go6976) on ORCO phosphorylation expressed in tissue culture cells or infused in to sensillum lymph supported the notion that a PKC was involved (Sargsyan et al., 2011). However, the PKC inhibitor Go6976, is only active against calcium dependent PKCs and is not expected to have activity against PKC98E that lacks the calcium binding $\mathrm{C} 2$ domain. Furthermore, these studies focused on flies carrying transposon insertions near the PKC53E and $\delta$ PKC kinase genes (Getahun et al., 2016). Neither transposon disrupts the coding sequence of the kinase gene (Thurmond et al., 2019), thus it is not clear that these transposons affect expression of the kinase genes. Here, we find no phenotype associated with RNAi knock-down of either of these PKCs in the olfactory neurons. Instead, our data supports the idea that PKC98E is the major kinase responsible for ORCO phosphorylation.

PKC98E was first identified in Drosophila over three decades ago (Schaeffer et al., 1989). This kinase is a member of the nPKC subtype that is thought to be activated by diacylglycerol (DAG) and phosphatidylserine (PS), but not calcium. PS and DAG activate the kinase through interactions with the regulatory $\mathrm{C} 1$ domain, releasing inhibition by the pseudosubstrate near the $\mathrm{N}$ terminus of the protein that maintains the kinase in an inactive form in the absence of activators (Johnson et al., 2000; Steinberg, 2008). The C1 domain functions as a calcium-independent lipid binding motif with high affinity to PS, a known PKC activator, while the $\mathrm{C} 2$ domain in classical PKCs binds lipids in a calcium-dependent manner (Johnson et al., 2000). PKC98E has the PS binding $\mathrm{C} 1$ domain, but the calcium-independent version of the $\mathrm{C} 2$ domain present in nPKCs (Nalefski and Falke, 1996). Indeed, calcium activation of the ORCO S289 kinase would be counterproductive because removal of the phosphate at S289 on neuronal activation is essential for slow desensitization (Guo et al., 2017). PKC98 $\mathrm{E}^{\mathrm{CAAX}}$ is able to phosphorylate ORCO at S289 and restore peak sensitivity to naive olfactory neurons in PKC98E FRT conditional mutants, but is defective for slow desensitization, consistent with the constitutively activated kinase impairing the ability of the olfactory neurons to effectively dephosphorylate Orco at S289. Our current model is that

\section{Anti pS289-Orco}
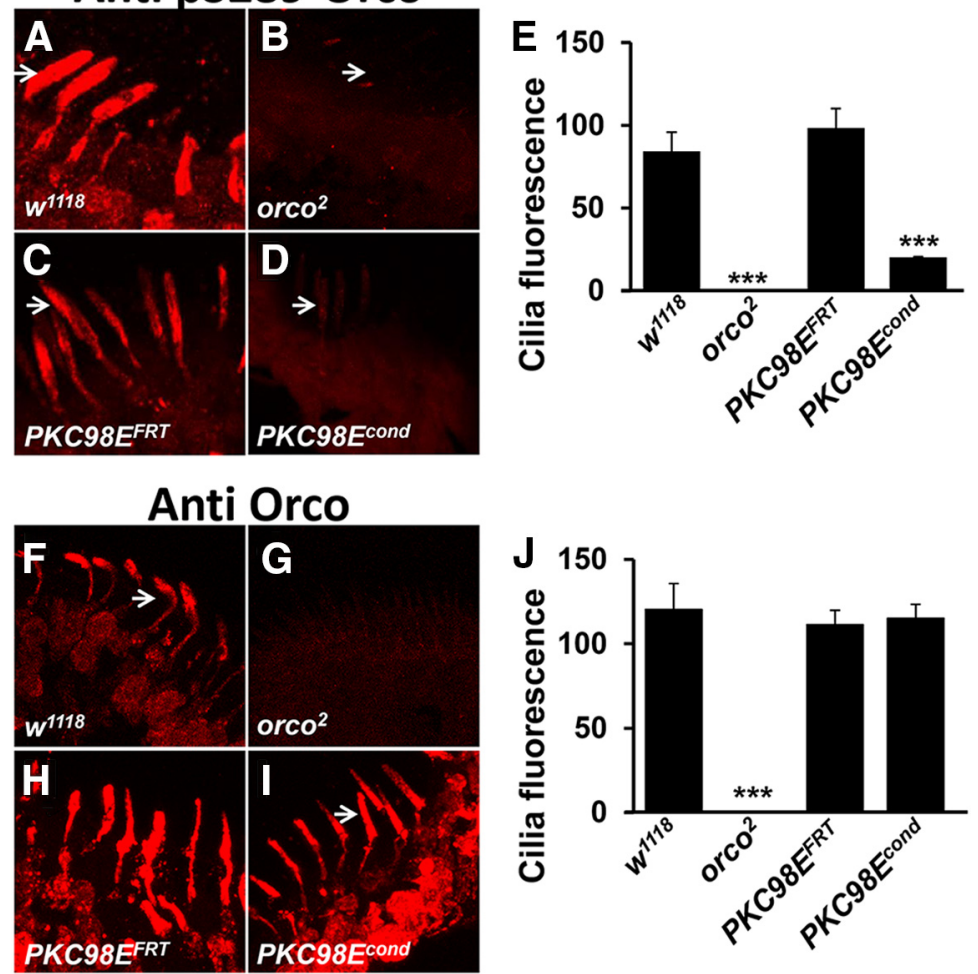

Figure 5. PKC98E conditional mutants are defective for $0 R C 0^{5289}$ phosphorylation in vivo. $\boldsymbol{A}-\boldsymbol{D}$, Representative images showing the phosphorylation of ORCO ${ }^{5289}$ in the $(\boldsymbol{A}) w^{1118}$ control, (B) orco mutants that lack ORCO, (C) PKC98E FRT, and (D) PKC98E FRT conditional mutants ( $P 0 R C 0-G A L 4 ;$ PKC98E FRT, UAS-FLP). Arrowheads point to representative olfactory neuron dendrites. $E$, The phosphorylation of $O R C 0^{5289}$ is strikingly reduced in PKC98E FRT conditional mutants $(p=0.009)$ and orco ${ }^{2}$ $\left(p=1.24 \times 10^{-5}\right)$ compared with wild-type controls $(p=0.009)$, but not in PKC98E FRT, UAS-FLP controls that lack the GAL4 driver $(p=0.41) ; n=5-10$, analysis by one-way ANOVA with post hoc Tukey's HSD test; $* * * p<0.01$ as compared with $w^{1118}$ control. $\boldsymbol{F}-\mathbf{I}$, Representative images showing total ORCO localization in the control and conditional mutants. Arrowheads denote representative olfactory neuron dendrites. $J$, The quantification shows the overall ORCO localization in olfactory neuron dendrites is not significantly different among the genotypes except for the orco ${ }^{2}$ mutant that lacks ORCO ( $n=15 ; p=0.75$ between wild-type and PKC98E FRT, UAS-FLP, and $p=0.59$ between wild-type and PKC98E conditional, $p=2.77 \times 10^{-6}$ between $w^{1118}$ and orco mutant) by one-way ANOVA with post hoc Tukey's HSD test.
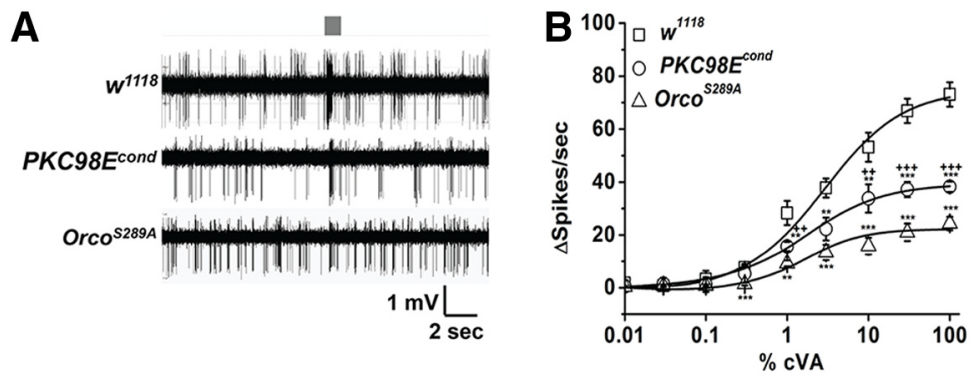

Figure 6. PKC98E FRT conditional mutant has reduced responsiveness to CVA. $A$, Sample trace for Or67d neurons from $w^{1118}$, PKC98E FRT conditional mutants (pORCO-GAL4; PKC98E FRT, UAS-FLP), and ORCO ${ }^{5289 A}$ flies (pORCO-GAL4/UAS-OrCO ${ }^{5289 A}$; orco $\left.^{2}\right)$ to $1 \% \mathrm{CVA}$. Stimulus duration $(300 \mathrm{~ms})$ is indicated by the gray bar. $\boldsymbol{B}$, Dose-response curve for cVA odor sensitivity for $w^{1118}$ and PKC98E FRT conditional mutant and ORCO $O^{5289 A}(n \geq 5)$. The sigmoidal curve for $\Delta$ spikes was plotted for different concentration of CVA with Hill fitting for the genotypes described. Error bars represent SEMs. One-way ANOVA analysis with post hoc Tukey's HSD test was done between control $\left(w^{1118}\right)$, PKC98E FRT conditional, and Orco ${ }^{5289 A}$ flies; $* * p<0.05$, $* * * p<0.01$ ( $p$ values between PKC98E FRT conditional mutant and $w^{1718}$ control flies are $p=0.3121,0.83454,0.65152$, $0.52124,0.041,0.032,0.044,0.0015$, and $4.36 \times 10^{-4}$ for $0.01 \%, 0.03 \%, 0.1 \%, 0.3 \%, 1 \%, 3 \%, 10 \%, 30 \%$, and $100 \%$ CVA, respectively; $p$ values comparing $0 R C 0^{5289 A}$ flies and $w^{1118}$ are $0.21764,0.97444,0.42962,0.00189,0.00272,0.00109,4.42$ $\times 10^{-4}, 7.05 \times 10^{-5}$, and $2.39 \times 10^{-5}$ for $0.01 \%, 0.03 \%, 0.1 \%, 0.3 \%, 1 \%, 3 \%, 10 \%, 30 \%$, and $100 \%$ cVA, respectively. The ANOVA comparison was also done between PKC98E FRT conditional and ORCO $0^{5289 A} ;++p<0.05,+++p<0.01(p$ values are $0.86982,0.79244,0.88431,0.20003,0.0144,0.12009,0.01867,0.00879$, and 0.00427 for $0.01 \%, 0.03 \%, 0.1 \%$, $0.3 \%, 1 \%, 3 \%, 10 \%, 30 \%$, and $100 \%$ cVA, respectively. 

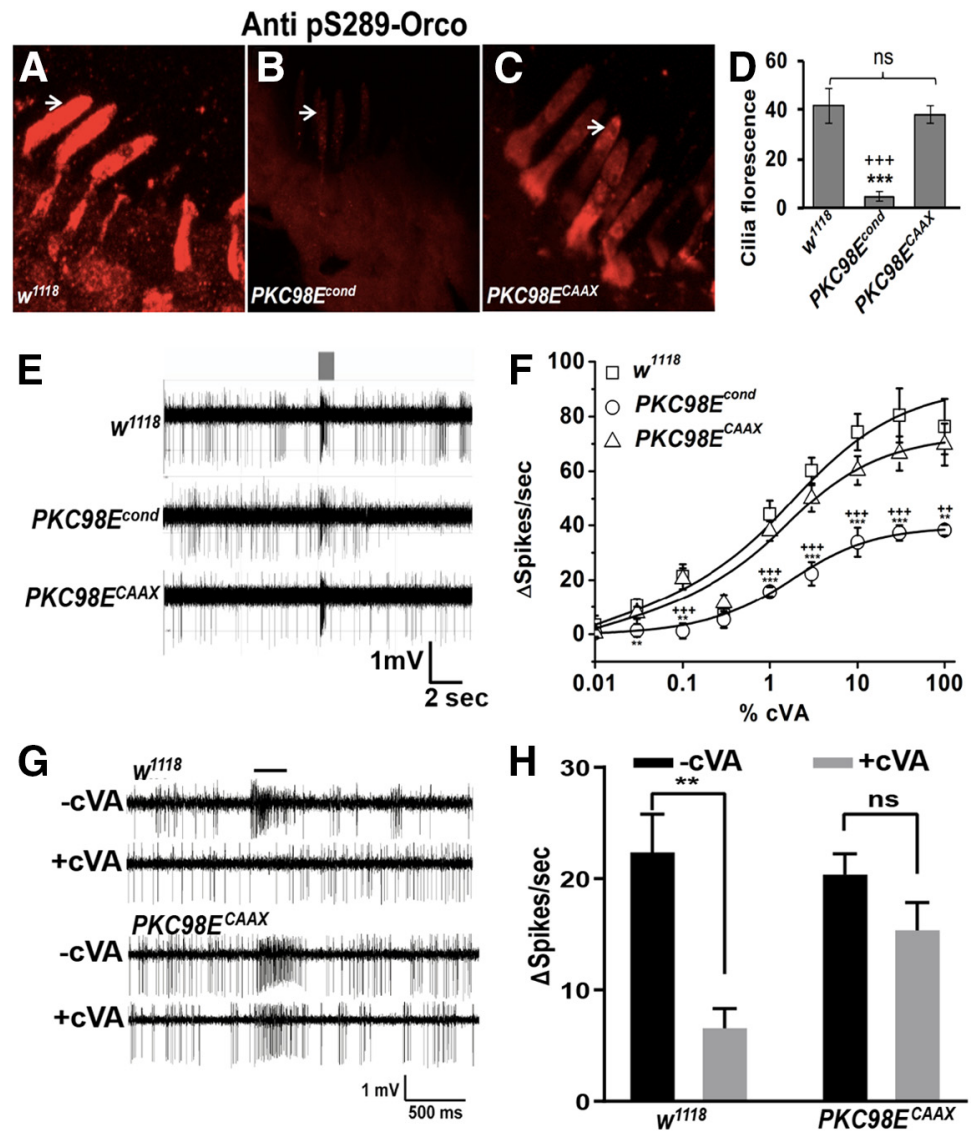

Figure 7. Expression of $P K C 98 E^{C A A X}$ in PKC98E conditional mutants restores sensitivity and ORCO 5289 phosphorylation. $A-C$, Examples of anti-phospho-ORCO on (A) wild-type control $\left(w^{1118}\right)$, (B) PKC98E FRT conditional mutants, (C) PKC98E FRT conditional mutants expressing PKC98E CAAX $^{\text {(pORCO-GAL4, UAS PKC98E }}{ }^{\text {CAAX }}$; PKC98E FRT, UAS-FLP). D, Quantitation of olfactory neuron dendrite fluorescence using phospho-S289 antiserum for the three genotypes; $n=5-10 ; * * * p<0.01$ $\left(p=1.23 \times 10^{-5}\right.$ for PKC98E FRT conditional and $w^{1118}$ control $) ;+++p<0.01\left(p=4.54 \times 10^{-5}\right.$ for PKC98E FRT conditional and PKC98EE $E^{\text {CAAX }}$ rescue); $p$ values were not significant between $w^{1118}$ and $\operatorname{PKC98E}^{\text {CAAX }}(p=0.396)$. $\boldsymbol{E}$, Sample traces for $w^{1118}$, PKC $98 E$ FRT conditional, and PKC98E FRT conditional mutants expressing PKC98E ${ }^{\text {CAAX }}$ to $1 \%$ CVA. $\boldsymbol{F}$, Dose-response curve to CVA for $w^{1118}$, PKC98E FRT conditional, and PKC98E FRT conditional expressing $P K C 98 E^{\text {CAAX }} ; n=5-10$. The sigmoidal curve for $\Delta$ spikes was plotted for different concentration of cVA with Hill fitting for the genotypes described; $* * p<0.05, * * * p<0.01$ (one-way ANOVA $p$ values between PKC98E FRT conditional and $w^{1118}$ for $0.01 \%, 0.03 \%, 0.1 \%, 0.3 \%, 1 \%, 3 \%, 10 \%, 30 \%$, and $100 \%$ CVA are $0.530,0.038,0.011,0.802$, $0.003,5.17 \times 10^{-5}, 0.002,0.009$, and 0.017 , respectively). ANOVA comparison between PKC98E FRT conditional and PKC98E ${ }^{\text {CAAX }}$ for the same CVA dilutions are $0.950,0.090,0.007,0.214,0.001,0.004,0.009,0.007$ and 0.011 , and between $P K C 98 E^{C A A X}$ and $w^{1118}$ are all below significance $(p=0.445,0.441,0.896,0.422,0.345,0.163,0.128,0.260$, and 0.618 for CVA doses, respectively). $G, \boldsymbol{H}$, Dominant PKC98E flies are defective in desensitization. $\boldsymbol{G}$ Representative responses of $w^{1718}$ and PKC98E ${ }^{\text {CAAX }}$ (pORCO-GAL4, UAS-PKC98EE ${ }^{\text {CAAX }}$; PKC98E FRT, UAS-FLP) to $1 \%$ CVA with and without CVA preexposure. $\boldsymbol{H}$, Desensitization of $w^{1118}$ (left) and $P K C 98 E^{\text {CAAX }}$ (right). Black bars represent without preexposure to CVA. Gray bars represent responses after a 1-h CVA exposure. Preexposure significantly reduces CVA responses of $w^{1118}(p=0.001$, two-tailed Student's $t$ test, $n=10)$, but does not significantly affect $\operatorname{PKC} 98 E^{\text {CAAX }}(p=0.101$, two-tailed Student's $t$ test, $n=10)$. PKC98E ${ }^{\text {CAAX }}$ shows impaired response reduction (interaction $F_{(1,36)}=4.605, p=0.039$, two-way ANOVA); $* * p<0.01$. Data are mean \pm SEM, ns, not significant.

calcium entry results in activation of a phosphatase, and inhibition of PKC98E activity. An intriguing possibility is that PKC98E is regulated by PS in the cytoplasmic leaflet of the dendrites. Mutants defective for $d A T P 8 B$, a PS translocase localized to the olfactory neuron dendrites (Ha et al., 2014), has modulatory defects similar to those of the PKC98E conditional mutants ( $\mathrm{Ha}$ et al., 2014; Liu et al., 2014; Guo et al., 2017). Future studies will explore the potential link between PS localization and PKC98E regulation in these neurons.

Most neurons show decaying neuronal activity in response to prolonged stimulation (Benda, 2021). Vertebrate Ors are Gprotein-coupled receptors (Buck and Axel, 1991) that trigger
cAMP-mediated opening of cyclic nucleotide-gated cation channels through activation of the G-protein, $\mathrm{G}_{\text {olf }}$ (Jones and Reed, 1989) and adenylate cyclase III (Pfeuffer et al., 1989; Wong et al., 2000). Calcium influx is a prominent feature of opening these channels. Sustained exposure to an odorant results in desensitization of olfactory neurons, and loss of odorant perception. Desensitization in vertebrate olfactory neurons involves a number of calciumdependent events that alter the activity of olfactory signaling components. For example, calcium entry into the vertebrate olfactory cilia triggers activation of calmodulin kinase II (CamII) to phosphorylate several important factors, including adenylate cyclase to inhibit cAMP production (Kurahashi and Menini, 1997; Wei et al., 1998) and activate the phosphodiesterase responsible for degrading cAMP in the olfactory neurons (Borisy et al., 1992; Boekhoff et al., 1996; Kurahashi and Menini, 1997). These calcium-dependent feedback mechanisms operate to produce desensitization in vertebrate olfactory neurons.

The slow desensitization in Drosophila olfactory neurons is distinct from previously reported desensitization mechanisms that operate over millisecond or second time scales (Das et al., 2011; Nagel and Wilson, 2011; Martelli et al., 2013; Cao et al., 2016; Gorur-Shandilya et al., 2017; Martelli and Fiala, 2019). Importantly, slow desensitization is important for chemotactic behaviors, as ORCO $^{\text {S289A }}$ mutants have impaired chemotaxis to food traps, and unlike wild-type flies, fail to avoid odorant traps containing the same odor as a preexposure (Guo et al., 2017). We suspect this mechanism is important for the ability to identify food sources in the presence of a pervasive background food odor. Regulating the shared Or subunit ORCO is an elegant mechanism to enable an olfactory neuron to undergo modulation, regardless of the tuning receptor subunit expressed by that cell. Dephosphorylation of ORCO at S289 and slow desensitization occurs on extended odorant stimulation, or by activation of the neurons using channelrhodopsin in the absence of odorants (Guo et al., 2017). Therefore, this modulatory mechanism is triggered by neuronal activity, regardless of how the neuron is depolarized. One explanation is that calcium entry into these neurons triggers activation of a phosphatase to remove phosphate at ORCO S289. The identity of the ORCO phosphatase is unknown. If substantiated, this would reveal that vertebrate and invertebrate olfactory sensitivity may both be modulated 
by calcium influxes but executed by divergent enzymatic programs.

\section{References}

Benda J (2021) Neural adaptation. Curr Biol 31:R110- R119.

Benton R, Vannice KS, Gomez-Diaz C, Vosshall LB (2009) Variant ionotropic glutamate receptors as chemosensory receptors in Drosophila. Cell 136:149-162.

Berger BM, Kim JH, Hildebrandt ER, Davis IC, Morgan MC, Hougland JL, Schmidt WK (2018) Protein isoprenylation in yeast targets $\mathrm{COOH}$-terminal sequences not adhering to the CaaX consensus. Genetics 210:13011316.

Blom N, Gammeltoft S, Brunak S (1999) Sequence and structure-based prediction of eukaryotic protein phosphorylation sites. J Mol Biol 294:13511362.

Boekhoff I, Kroner C, Breer H (1996) Calcium controls second-messenger signalling in olfactory cilia. Cell Signal 8:167-171.

Borisy FF, Ronnett GV, Cunningham AM, Juilfs D, Beavo J, Snyder SH (1992) Calcium/calmodulin-activated phosphodiesterase expressed in olfactory receptor neurons. J Neurosci 12:915-923.

Brand A, Perrimon N (1993) Targeted gene expression as a means of altering cell fates and generating dominant phenotypes. Development 118:401415.

Buck L, Axel R (1991) A novel multigene family may encode odorant receptors: a molecular basis for odor recognition. Cell 65:175-187.

Cao LH, Jing BY, Yang D, Zeng X, Shen Y, Tu Y, Luo DG (2016) Distinct signaling of Drosophila chemoreceptors in olfactory sensory neurons. Proc Natl Acad Sci USA 113:E902-E911.

Clyne PJ, Warr CG, Freeman MR, Lessing D, Kim J, Carlson JR (1999) A novel family of divergent seven-transmembrane proteins: candidate odorant receptors in Drosophila. Neuron 22:327-338.

Couto A, Alenius M, Dickson BJ (2005) Molecular, anatomical, and functional organization of the Drosophila olfactory system. Curr Biol 15:1535-1547.

Das S, Sadanandappa MK, Dervan A, Larkin A, Lee JA, Sudhakaran IP, Priya R, Heidari R, Holohan EE, Pimentel A, Gandhi A, Ito K, Sanyal S, Wang JW, Rodrigues V, Ramaswami M (2011) Plasticity of local GABAergic interneurons drives olfactory habituation. Proc Natl Acad Sci USA 108: E646-E654.

Elmore T, Ignell R, Carlson JR, Smith DP (2003) Targeted mutation of a Drosophila odor receptor defines receptor requirement in a novel class of sensillum. J Neurosci 23:9906-9912.

Fain GL, Matthews HR, Cornwall MC, Koutalos Y (2001) Adaptation in vertebrate photoreceptors. Physiol Rev 81:117-151.

FlyBase Consortium (1999) The FlyBase database of the Drosophila genome projects and community literature. Nucleic Acids Res 27:85-88.

Getahun MN, Wicher D, Hansson BS, Olsson SB (2012) Temporal response dynamics of Drosophila olfactory sensory neurons depends on receptor type and response polarity. Front Cell Neurosci 6:54.

Getahun MN, Olsson SB, Lavista-Llanos S, Hansson BS, Wicher D (2013) Insect odorant response sensitivity is tuned by metabotropically autoregulated olfactory receptors. PLoS One 8: e58889.

Getahun MN, Thoma M, Lavista-Llanos S, Keesey I, Fandino RA, Knaden M, Wicher D, Olsson SB, Hansson BS (2016) Intracellular regulation of the insect chemoreceptor complex impacts odour localization in flying insects. J Exp Biol 219:3428-3438.

Gorur-Shandilya S, Demir M, Long J, Clark DA, Emonet T (2017) Olfactory receptor neurons use gain control and complementary kinetics to encode intermittent odorant stimuli. Elife 6:e27670.

Gratz SJ, Cummings AM, Nguyen JN, Hamm DC, Donohue LK, Harrison MM, Wildonger J, O'Connor-Giles KM (2013) Genome engineering of Drosophila with the CRISPR RNA-guided Cas9 nuclease. Genetics 194:1029-1035.

Guo H, Kunwar K, Smith D (2017) Odorant receptor sensitivity modulation in Drosophila. J Neurosci 37:9465-9473.
Ha TS, Xia R, Zhang H, Jin X, Smith DP (2014) Lipid flippase modulates olfactory receptor expression and odorant sensitivity in Drosophila. Proc Natl Acad Sci USA 111:7831-7836.

Hallem EA, Carlson JR (2004) The odor coding system of Drosophila. Trends Genet 20:453-459.

Han C, Jan LY, Jan YN (2011) Enhancer-driven membrane markers for analysis of nonautonomous mechanisms reveal neuron-glia interactions in Drosophila. Proc Natl Acad Sci USA 108:9673-9678.

Johnson JE, Giorgione J, Newton AC (2000) The C1 and C2 domains of protein kinase $\mathrm{C}$ are independent membrane targeting modules, with specificity for phosphatidylserine conferred by the $\mathrm{C} 1$ domain. Biochemistry 39:11360-11369.

Jones DT, Reed RR (1989) Golf: an olfactory neuron specific-G protein involved in odorant signal transduction. Science 244:790795.

Kato A, Touhara K (2009) Mammalian olfactory receptors: pharmacology, G protein coupling and desensitization. Cell Mol Life Sci 66:3743-3753.

Kondo S, Ueda R (2013) Highly improved gene targeting by germline-specific Cas9 expression in Drosophila. Genetics 195:715-721.

Kurahashi T, Menini A (1997) Mechanism of odorant adaptation in the olfactory receptor cell. Nature 385:725-729.

Larsson MC, Domingos AI, Jones WD, Chiappe ME, Amrein H, Vosshall LB (2004) Or83b encodes a broadly expressed odorant receptor essential for Drosophila olfaction. Neuron 43:703-714.

Laughlin JD, Ha TS, Jones DN, Smith DP (2008) Activation of pheromonesensitive neurons is mediated by conformational activation of pheromone-binding protein. Cell 133:1255-1265.

Liu YC, Pearce MW, Honda T, Johnson TK, Charlu S, Sharma KR, Imad M, Burke RE, Zinsmaier KE, Ray A, Dahanukar A, de Bruyne M, Warr CG (2014) The Drosophila melanogaster phospholipid flippase dATP8B is required for odorant receptor function. PLoS Genet 10:e1004209.

Martelli C, Fiala A (2019) Slow presynaptic mechanisms that mediate adaptation in the olfactory pathway of Drosophila. Elife 8:e43735.

Martelli C, Carlson JR, Emonet T (2013) Intensity invariant dynamics and odor-specific latencies in olfactory receptor neuron response. J Neurosci 33:6285-6297.

Nagel KI, Wilson RI (2011) Biophysical mechanisms underlying olfactory receptor neuron dynamics. Nat Neurosci 14:208-216.

Nalefski EA, Falke JJ (1996) The C2 domain calcium-binding motif: structural and functional diversity. Protein Sci 5:2375-2390.

Olsen SR, Wilson RI (2008) Lateral presynaptic inhibition mediates gain control in an olfactory circuit. Nature 452:956-960.

Pfeuffer E, Mollner S, Lancet D, Pfeuffer T (1989) Olfactory adenylyl cyclase. Identification and purification of a novel enzyme form. J Biol Chem 264:18803-18807.

Pitts S, Pelser E, Meeks J, Smith D (2016) Odorant responses and courtship behaviors influenced by at 4 neurons in Drosophila. PLoS One 11: e0162761.

Ronderos DS, Lin CC, Potter CJ, Smith DP (2014) Farnesol-detecting olfactory neurons in Drosophila. J Neurosci 34:3959-3968.

Sargsyan V, Getahun MN, Llanos SL, Olsson SB, Hansson BS, Wicher D (2011) Phosphorylation via PKC regulates the function of the Drosophila odorant co-receptor. Front Cell Neurosci 5:5.

Sato K, Pellegrino M, Nakagawa T, Nakagawa T, Vosshall LB, Touhara K (2008) Insect olfactory receptors are heteromeric ligand-gated ion channels. Nature 452:1002-1006.

Schaeffer E, Smith D, Mardon G, Quinn W, Zuker CS (1989) Isolation and characterization of two new Drosophila protein kinase C genes, including one specifically expressed in photoreceptor cells. Cell 57:403-412.

Schafer WR, Kim R, Sterne R, Thorner J, Kim SH, Rine J (1989) Genetic and pharmacological suppression of oncogenic mutations in ras genes of yeast and humans. Science 245:379-385.

Smith DP, Ranganathan R, Hardy R, Marx J, Tsuchida T, Zuker C (1991) Photoreceptor deactivation and retinal degeneration mediated by a photoreceptor-specific protein kinase C. Science 254:1478-1484.

Sommese RF, Ritt M, Swanson CJ, Sivaramakrishnan S (2017) The role of regulatory domains in maintaining autoinhibition in the multidomain kinase PKC $\alpha$. J Biol Chem 292:2873-2880. 
Spradling AC, Rubin GM (1982) Transposition of cloned P elements into Drosophila germ line chromosomes. Science 218:341-347.

Steinberg SF (2008) Structural basis of protein kinase C isoform function. Physiol Rev 88:1341-1378.

Thurmond J, Goodman JL, Strelets VB, Attrill H, Gramates LS, Marygold SJ, Matthews BB, Millburn G, Antonazzo G, Trovisco V, Kaufman TC, Calvi BR; FlyBase Consortium (2019) FlyBase 2.0: the next generation. Nucleic Acids Res 47:D759-D765.

Tremmel DM, Resad S, Little CJ, Wesley CS (2013) Notch and PKC are involved in formation of the lateral region of the dorso-ventral axis in Drosophila embryos. PLoS One 8:e67789.

Vosshall LB, Amrein H, Morozov PS, Rzhetsky A, Axel R (1999) A spatial map of olfactory receptor expression in the Drosophila antenna. Cell 96:725-736.
Wei J, Zhao AZ, Chan GC, Baker LP, Impey S, Beavo JA, Storm DR (1998) Phosphorylation and inhibition of olfactory adenylyl cyclase by CaM kinase II in neurons: a mechanism for attenuation of olfactory signals. Neuron 21:495-504.

Wicher D, Schäfer R, Bauernfeind R, Stensmyr MC, Heller R, Heinemann SH, Hansson BS (2008) Drosophila odorant receptors are both ligandgated and cyclic-nucleotide-activated cation channels. Nature 452:10071011.

Wilson RI (2013) Early olfactory processing in Drosophila: mechanisms and principles. Annu Rev Neurosci 36:217-241.

Wong ST, Trinh K, Hacker B, Chan GC, Lowe G, Gaggar A, Xia Z, Gold GH, Storm DR (2000) Disruption of the Type III adenylyl cyclase gene leads to peripheral and Behavioral anosmia in transgenic mice. Neuron 27:487-497. 